Article

\title{
Evaluating the Use of an Object-Based Approach to Lithological Mapping in Vegetated Terrain
}

\author{
Stephen Grebby ${ }^{1, *}$, Elena Field ${ }^{2}$ and Kevin Tansey ${ }^{3}$ \\ 1 Nottingham Geospatial Institute, The University of Nottingham, Innovation Park, \\ Nottingham NG7 2TU, UK \\ 2 British Antarctic Survey, Natural Environment Research Council, High Cross, Madingley Road, \\ Cambridge CB3 0ET, UK; eleeld@bas.ac.uk \\ 3 Department of Geography, University of Leicester, Leicester LE1 7RH, UK; kjt7@le.ac.uk \\ * Correspondence: stephen.grebby@nottingham.ac.uk; Tel.: +44-115-951-3883
}

Academic Editors: Bailang Yu, Lenio Soares Galvao and Prasad S. Thenkabail

Received: 19 July 2016; Accepted: 11 October 2016; Published: 14 October 2016

\begin{abstract}
Remote sensing-based approaches to lithological mapping are traditionally pixel-oriented, with classification performed on either a per-pixel or sub-pixel basis with complete disregard for contextual information about neighbouring pixels. However, intra-class variability due to heterogeneous surface cover (i.e., vegetation and soil) or regional variations in mineralogy and chemical composition can result in the generation of unrealistic, generalised lithological maps that exhibit the "salt-and-pepper" artefact of spurious pixel classifications, as well as poorly defined contacts. In this study, an object-based image analysis (OBIA) approach to lithological mapping is evaluated with respect to its ability to overcome these issues by instead classifying groups of contiguous pixels (i.e., objects). Due to significant vegetation cover in the study area, the OBIA approach incorporates airborne multispectral and LiDAR data to indirectly map lithologies by exploiting associations with both topography and vegetation type. The resulting lithological maps were assessed both in terms of their thematic accuracy and ability to accurately delineate lithological contacts. The OBIA approach is found to be capable of generating maps with an overall accuracy of $73.5 \%$ through integrating spectral and topographic input variables. When compared to equivalent per-pixel classifications, the OBIA approach achieved thematic accuracy increases of up to $13.1 \%$, whilst also reducing the "salt-and-pepper" artefact to produce more realistic maps. Furthermore, the OBIA approach was also generally capable of mapping lithological contacts more accurately. The importance of optimising the segmentation stage of the OBIA approach is also highlighted. Overall, this study clearly demonstrates the potential of OBIA for lithological mapping applications, particularly in significantly vegetated and heterogeneous terrain.
\end{abstract}

Keywords: lithological mapping; OBIA; airborne LiDAR; multispectral; Troodos ophiolite

\section{Introduction}

The use of remotely sensed spectral imagery provides a means of easing both the financial and logistical burden of traditional field-based lithological mapping. This is particularly the case when image classification algorithms are utilised since they provide the capability to automatically identify and map lithologies rapidly over vast areas, whilst also reducing the subjectivity associated with visual interpretation of the imagery [1].

An extensive range of classification algorithms has been used in conjunction with multi- and hyperspectral imagery for lithological mapping. These can be categorised in a variety of different ways-for instance, according to whether an algorithm requires training data (i.e., supervised vs. unsupervised), its underlying statistical assumptions (i.e., parametric vs. non-parametric), or on the 
basis of how it classifies image elements (e.g., per-pixel, and sub-pixel) [2]. To date, image classifiers employed for lithological mapping purposes have been almost exclusively pixel-based, performing classification on a per-pixel or sub-pixel basis with complete disregard for any contextual information about neighbouring pixels [3].

Per-pixel classification algorithms operate by independently assigning each image pixel to a single lithological class by identifying the closest match between a pixel spectrum and the reference spectra for a set of known lithologies [4]. Popular algorithms employed for per-pixel lithological classification include the Maximum Likelihood classifier [5,6] and artificial neural networks $[7,8]$. With regards to producing a generalised lithological map, a major limitation of the per-pixel classification approach is that it assumes each image pixel corresponds to an area on the ground that contains only a single lithology. In reality, this is arguably rarely the case, with pixels more likely to correspond to areas containing mixtures of different surface materials, whether that be multiple lithologies or vegetation-covered outcrops. Varying degrees of mixing between neighbouring pixels can cause significant intra-class spectral variation, resulting in per-pixel classification outputs that exhibit "salt-and-pepper" noise (owing to isolated, spurious pixel classifications) and poorly defined contacts [9].

Sub-pixel classification approaches offer a means of overcoming the issues associated with mixed pixels because they can assign pixels a degree of membership to multiple classes. In general, such algorithms employ spectral unmixing analysis to deconvolve image pixel spectra to quantify the relative fractional abundances of the various constituent surface materials [10]. To achieve this, the spectral signatures of the different surface materials (i.e., endmembers) must first be identified. However, this usually requires prior knowledge of all endmembers in a scene, with the meaningfulness of the unmixing results severely limited by the failure to adequately characterise all endmembers [11,12]. Furthermore, the process of generating a generalised lithological map from numerous abundance maps is somewhat subjective and often requires subsequent visual interpretation of lithological contacts [13].

Although the application of remote sensing to lithological mapping is well-established, vegetation cover still remains one of the main factors limiting its wider utility. This is because as little as $10 \%-30 \%$ vegetation cover (e.g., green grass, dry grass, and lichen) can be enough to obscure or mask the spectral signatures of underlying lithologies $[14,15]$. The challenge posed by vegetation cover is clearly reflected in the literature, with the vast majority of studies circumventing this issue by focussing on arid environments that are largely barren [4]. Nevertheless, there have been efforts to try to overcome this issue, most notably through the employment of sub-pixel classification approaches to spectrally unmix the vegetation response from that of the underlying lithology [16,17]. Beyond the capabilities of spectral unmixing (with respect to the combination of the characteristics of the spectral imagery, vegetation and suite of lithologies), the use of proxy-based approaches can prove effective. One such indirect approach is to exploit geobotanical relationships [18]. This involves recognising a correlation between lithologies and vegetation type, and then using the spectral signatures of specific types of vegetation as proxies for mapping their associated lithological units in the imagery [19]. Similarly, there is also promise in exploiting information on surface morphology, which can reflect erosional and weathering differences between lithologies $[20,21]$. This typically involves using topographic information [6] or radar-derived surface texture [22] in combination with spectral data to help augment lithological classifications. However, despite the potential of indirect mapping, geobotanical and surface morphology characteristics of lithologies are not always strictly exclusive, and can cause significant intra-class heterogeneity and overlap between different classes. As a result, per-pixel classification attempts can still exhibit the undesired "salt-and-pepper" artefact and be affected by problems in accurately delineating lithological contacts as contiguous pixels, irrespective of whether sophisticated classifiers are employed [23].

Recent advances in classification techniques have led to a paradigm shift in many fields, from the classical pixel-based approach to instead focussing on image objects [24]. The object-based image analysis (OBIA) approach-also commonly referred to as geographic object-based image analysis 
(GEOBIA) - involves segmenting an image into homogeneous regions (i.e., objects) by grouping contiguous pixels that are relatively similar in terms of both their spectral and spatial characteristics [25]. Grouping pixels enables contextual (neighbourhood) information to be incorporated and thus results in the creation of image objects that represent "meaningful" entities (e.g., buildings, trees, fields, or perhaps even rock outcrops) in an image [24]. Image objects therefore have additional spectral (e.g., mean, median, minimum and maximum band values, band variance) and spatial attributes (e.g., shape, size, association with neighbouring objects) in comparison to individual pixels [26]. One of the main advantages of OBIA over per-pixel approaches is that using objects negates the impact of intra-class heterogeneity observed at the pixel-level, therefore eliminating the "salt-and-pepper" artefact [27]. Consequently, OBIA has been used extensively for a variety of applications, including forestry [28], habitat mapping [29], land use/land cover mapping [30], landform mapping [31,32] and change detection [33], with numerous studies reporting that higher classification accuracies can be achieved through the OBIA approach in comparison to pixel-based approaches [34-36].

Despite seemingly having the potential to eradicate the issues associated with pixel-based approaches, the application of OBIA to lithological mapping has received minimal attention. Preliminary studies by Lucieer et al. [37] and van der Werff et al. [38] indicated the ability to distinguish lithological units in southern Mongolia and Mars, respectively, through segmentation of spectral satellite imagery. More recently, OBIA has been employed to map volcanic units and landforms on active volcanoes in Indonesia [39,40], and to delineate geologically-controlled vegetation types in the Kruger National Park, South Africa [41]. However, the potential benefit of employing OBIA over pixel-based classification approaches for lithological mapping has yet to be realised.

This study aims to help address this by evaluating the capability of an OBIA approach for producing detailed lithological maps with accurately defined contacts, for an area of the Troodos ophiolite, Cyprus. Due to pervasive vegetation cover, an indirect approach to mapping is employed, based on the novel strategy of segmenting airborne multispectral imagery and airborne Light Detection And Ranging (LiDAR) data to exploit geobotanical and topographic relationships with the lithologies. Accordingly, this study provides a robust test for a scenario in which OBIA is anticipated to be most effective. Moreover, the Troodos study area is well-known, therefore enabling the performance of the OBIA mapping approach to be readily assessed and directly compared with previous results obtained using equivalent per-pixel classification approaches. Accordingly, to the best of our knowledge, this study represents the most compressive assessment of OBIA in the specific context of lithological mapping to date.

\section{Materials and Methods}

\subsection{Study Area}

The Troodos ophiolite forms a dome-like structure in the central region of the eastern Mediterranean island of Cyprus, and represents an uplifted slice of oceanic crust and lithospheric mantle that was produced through sea-floor spreading [42]. The stratigraphy of the ophiolite is inverted with respect to topography, with the mantle sequence (comprising harzburgites, dunites and a serpentinite diapir) outcropping at the highest elevations, and a largely gabbroic plutonic complex, sheeted dyke complex, lava sequence and oceanic sediments outcropping at decreasing elevation along the northern slopes of the Troodos mountain range [43]. The study area is located on the northern flank of the range in the Larnaca graben and encompasses the contact between the lava sequence and the overlying sedimentary cover sequences (Figure 1). It covers approximately $16 \mathrm{~km}^{2}$ and contains four main lithological units: the Basal Group (comprising $80 \%-90 \%$ dykes and $10 \%-20 \%$ lavas), Pillow Lavas, late-Cretaceous to early-Miocene chalky marls of the Lefkara Formation and Alluvium-colluvium. Alluvium-colluvium, as defined on the existing maps, is a generic unit that corresponds to Quaternary sediments that have been deposited fluvially or through local erosion. These mostly comprise regoliths derived from Lefkara Formation and Pilliow Lava parent rocks, and to 
a lesser extent, fanglomerates. The primary and secondary constituent minerals for the lithological units—based on petrological descriptions by Gass [44]—are detailed in Table 1.

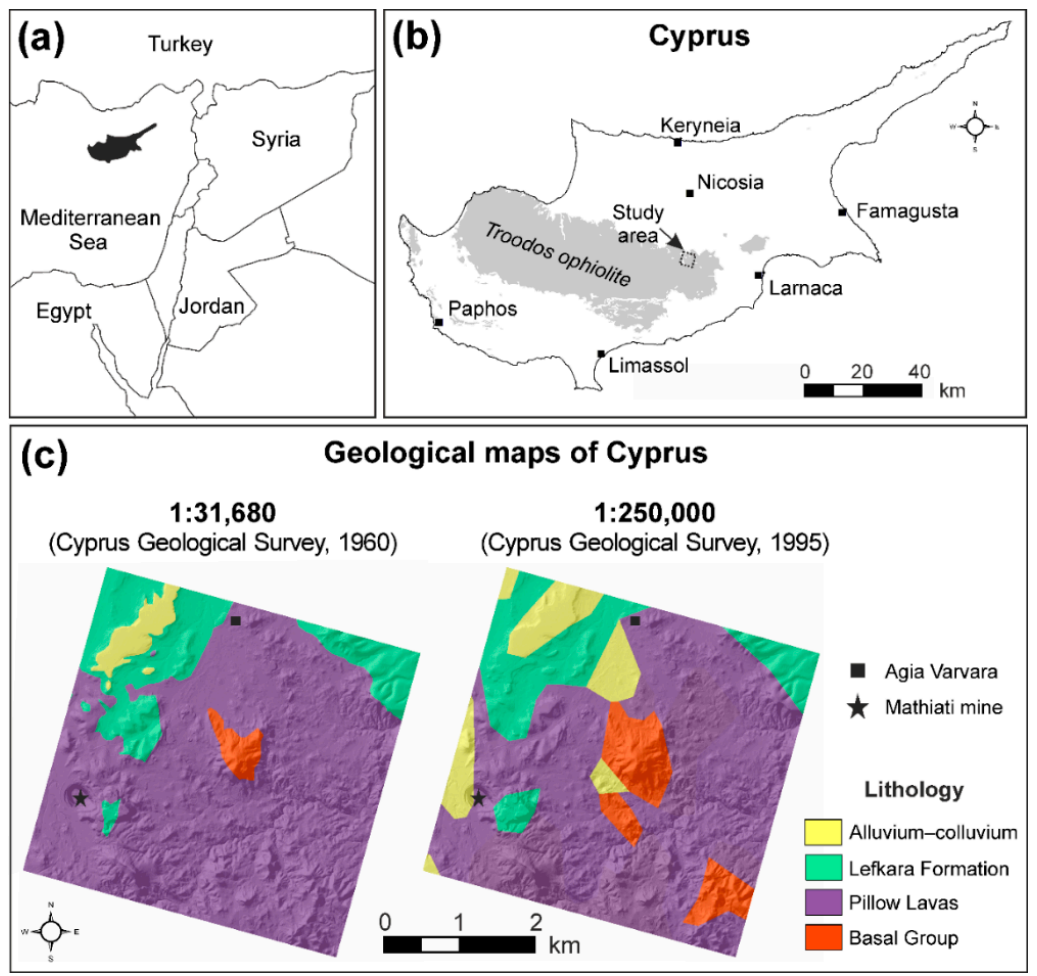

Figure 1. Location and setting of the study area: (a) Eastern Mediterranean region; (b) Island of Cyprus; and (c) existing generalised 1:31,680 [44] and 1:250,000 [45] scale geological maps of the study area. Digital geology data provided by the Cyprus Geological Survey Department.

Vegetation is ubiquitous and abundant, covering $30 \%-90 \%$ of the surface and resulting in a heterogeneous surface mixture of vegetation and rock/soil throughout the study area (Figure 2). Nonetheless, strong correlations between lithology and topography [46], and lithology and vegetation have been well documented in the study area [23]. For instance, crops (including olive trees) are predominantly associated with Alluvium-colluvium, lichen is almost exclusively found growing on Pillow Lava outcrops, whereas grasses and shrubs (plus trees) are typically observed growing on both the Lefkara Formation and Basal Group units, respectively. Anthropogenic impact on the landscape is relatively minor, being largely confined to the abandoned Mathiati mine in the southwest and Agia Varvara village in the north of the study area.

Table 1. Primary and secondary constituent minerals of the lithological units.

\begin{tabular}{cl}
\hline Lithological Unit & \multicolumn{1}{c}{ Constituent Minerals } \\
\hline Alluvium-colluvium & $\begin{array}{l}\text { Mineralogy reflects that of parent Lefkara Formation, Pillow Lavas and } \\
\text { fanglomerate rocks, with minor variations due to weathering }\end{array}$ \\
\hline Lefkara Formation & $\begin{array}{l}\text { Calcite, aragonite, illite, chlorite, kaolinite, montmorillonite, chalcedony } \\
\text { and quartz }\end{array}$ \\
\hline Pillow Lavas & $\begin{array}{l}\text { Labradorate, andesine, diopside, magnetite, quartz, opal, calcite, } \\
\text { chlorite, celadonite, goethite, natrolite, olivine, hematite, } \\
\text { montmorillonite and analcime }\end{array}$ \\
\hline Basal Group & $\begin{array}{l}\text { Quartz, albite, diopside, epidote, actinolite, chlorite, calcite, goethite, } \\
\text { magnetite, hypersthene, andesine and labradorite }\end{array}$ \\
\hline
\end{tabular}




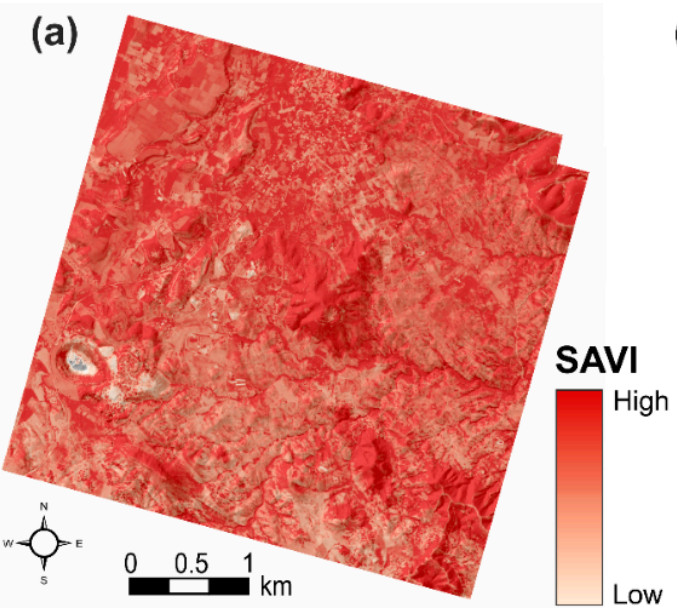

(b)

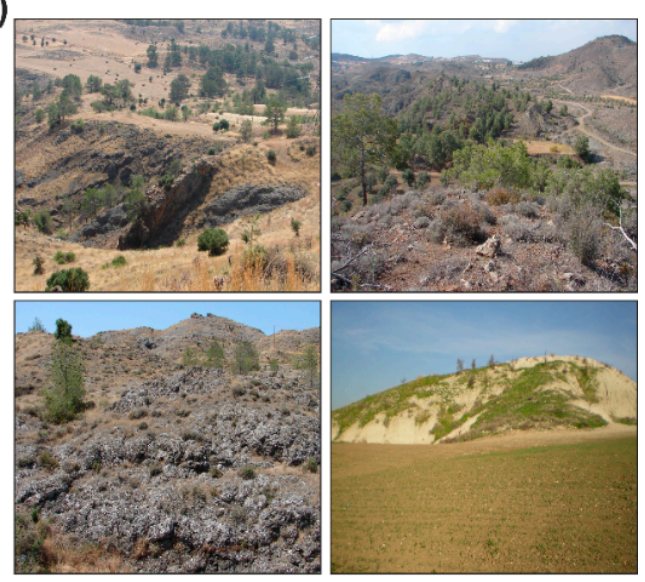

Figure 2. Widespread vegetation cover within the study area: (a) soil-adjusted Vegetation Index (SAVI) map indicating relative fractional vegetation abundance; and (b) field photographs illustrating the different types of vegetation present.

\subsection{Remote Sensing Data}

Airborne LiDAR data and Airborne Thematic Mapper (ATM) multispectral imagery were acquired simultaneously over the study area in May 2005 by the UK Natural Environment Research Council Airborne Research Facility. The airborne LiDAR data were acquired at an average flying altitude of $2550 \mathrm{~m}$ using an ALTM-3033 system operating with a laser pulse repetition rate of $33 \mathrm{kHz}$ and a half-scan angle of $\pm 19.4^{\circ}$ either side of the nadir. The airborne LiDAR point data were delivered as ASCII files containing the $\mathrm{x}-\mathrm{y}-\mathrm{z}$ coordinates of all first and last returns in the WGS84 Universal Transverse Mercator (UTM) zone 36-North coordinate system. Each data point was classified as corresponding to either the ground or non-ground features using the triangulated irregular network densification algorithm [47] implemented in the TerraScan software package (Terrasolid Ltd., Helsinki, Finland). A 4-m digital terrain model (DTM) was then generated by interpolating all ground points using a kriging algorithm [46].

The Daedalus 1268 multispectral scanner was used to acquire the ATM imagery; comprising 11 wavebands located in the visible/near-infrared (VNIR; bands 1-8), short-wave infrared (SWIR; bands 9-10) and thermal infrared (TIR; band 11) regions of the electromagnetic spectrum. The imagery was delivered as five Level $1 \mathrm{~b}$ Hierarchical Data Format files with radiometric calibration algorithms applied and aircraft navigation information appended. Through use of the appropriate tools in the ENVI software package (Harris Geospatial Solutions, Broomfield, CO, USA), each image strip was subsequently converted to at-sensor radiance, geo-corrected and corrected for limb-brightening effects [23]. A seamless 4-m ATM image for the study area was then generated by mosaicking and co-registering the five geo-corrected images to the LiDAR DTM. The ATM wavebands 1 and 11 were discarded as they fall outside the wavelength region of interest.

\subsection{Lithological Mapping Using OBIA}

The OBIA approach to lithological mapping comprises three main steps: (i) input feature selection; (ii) segmentation; and (iii) classification. These steps are described in detail below.

\subsubsection{Input Feature Selection}

Vegetation cover in the study area is sufficiently ubiquitous and abundant to severely limit the direct mapping of lithologies through recognition of their spectral signatures because the pixel spectra in the ATM imagery are dominated by the spectral characteristics of the overlying vegetation [48]. Successful mapping therefore depends upon establishing a proxy-based approach, which uses 
alternative information to characterise and indirectly map the various lithologies. As mentioned previously, lithologies in the study area are strongly associated with specific vegetation types, and different units also exhibit relatively distinct topographic characteristics. Previous studies have demonstrated the ability to effectively exploit these relationships to map lithology by way of ATM-derived spectral characteristics of the vegetation itself [23] and LiDAR-derived geomorphometric variables (e.g., slope, curvature, and surface roughness) [46]. These studies were based on per-pixel classification using an artificial neural network known as the Kohonen Self-Organizing Map (SOM). To enable direct comparison with the results of these previous pixel-based studies, the same sets of input features are used in determining the efficacy of the OBIA approach to lithological mapping. These sets of input features are summarised in Table 2.

Table 2. Summary of the sets of input features used in the OBIA approach.

\begin{tabular}{cc}
\hline Dataset & \multicolumn{1}{c}{ Input Features } \\
\hline Topographic characteristics & $\begin{array}{l}\text { Slope, absolute profile curvature, absolute plan curvature, residual } \\
\text { roughness, hypsometric integral }\end{array}$ \\
\hline Spectral (vegetation) characteristics \\
\hline ATM 9 & ATM bands 2-10 \\
\hline ATM PC & $\begin{array}{l}\text { First three principal component (PC) bands derived from analysis of } \\
\text { ATM 9 dataset }{ }^{\text {a }}\end{array}$ \\
\hline ATM MNF & $\begin{array}{l}\text { First four Minimum Noise Fraction (MNF) bands derived from } \\
\text { transformation of ATM 9 dataset }\end{array}$ \\
\hline Integrated spectral-topographic characteristics \\
\hline ATM-Li & $\begin{array}{l}\text { ATM bands 2-10, slope, absolute profile curvature, absolute plan } \\
\text { curvature, residual roughness, hypsometric integral }\end{array}$ \\
\hline ATM-Li MNF & $\begin{array}{l}\text { First five Minimum Noise Fraction (MNF) bands derived from } \\
\text { transformation of ATM-Li dataset }\end{array}$ \\
\hline Accounting for 97.5\% of the total scene variance for the ATM 9 dataset; ${ }^{\text {b }}$ Accounting for 98.7\% of the \\
cumulative eigenvalues for the ATM 9 dataset; ${ }^{c}$ Accounting for 98.3\% of the cumulative eigenvalues for the \\
ATM-Li dataset.
\end{tabular}

\subsubsection{Segmentation}

A critical step in the OBIA approach is the segmentation of an image into homogeneous objects, comprising groups of contiguous pixels with similar characteristics. In this study, segmentation was achieved using the multi-scale segmentation algorithm embedded in the commercial software eCognition Developer 9.0 (Trimble, Munich, Germany). This algorithm employs a bottom-up approach that begins with pixel-sized objects and sequentially merges them into larger objects according to a homogeneity criterion [25]. This criterion is intended to minimise increases in heterogeneity that may arise following the merging of two adjacent objects. Here, heterogeneity is a quantitative measure defined in terms of a combination of an object's colour and shape, where colour refers to the spectral heterogeneity of an object (i.e., the standard deviation of the values of encompassed pixels), and shape describes both the smoothness of its border and its compactness (i.e., length of its border relative to its size) [49]. During segmentation, neighbouring objects are merged provided that the heterogeneity of the resulting object does not increase beyond a defined threshold, known as the scale parameter. If the increase in heterogeneity exceeds this threshold, then the objects will not be merged and the segmentation process is halted. In general, smaller scale parameter values lead to fewer objects being merged, therefore resulting in the creation of relatively small image objects [50].

Appropriate image segmentation parameters for each input dataset were determined through a heuristic approach, as is commonly implemented as standard practice [27,50]. This iterative 
"trial-and-error" approach involved visually evaluating the segmentation results obtained using numerous combinations of parameter weightings for several fixed scale values. Selection of the initial parameter values was guided by past experience and expert physiographical knowledge of the study area, with a view to generating a detailed lithological map with accurately defined lithological contacts. Small scale parameter values were favoured in order to preserve spatial detail and to avoid under-segmentation, whereby heterogeneous image objects are created which are more likely to encompass multiple lithological units (Figure 3). The colour parameter was given a high relative weighting since spectral information (i.e., both ATM-derived spectral and topographic) is a much more defining attribute than shape in discriminating lithologies. With respect to the individual shape constituents, the relative weighting of smoothness was set considerably higher than that of compactness to place greater emphasis on the delineation of contacts between lithologies. For each dataset, the optimum segmentation parameter values were determined as those which produced image objects that most closely correspond to homogeneous physiographical features of geological relevance (e.g., hummocks, and crop fields). The parameter values used for image segmentation are shown in Table 3.
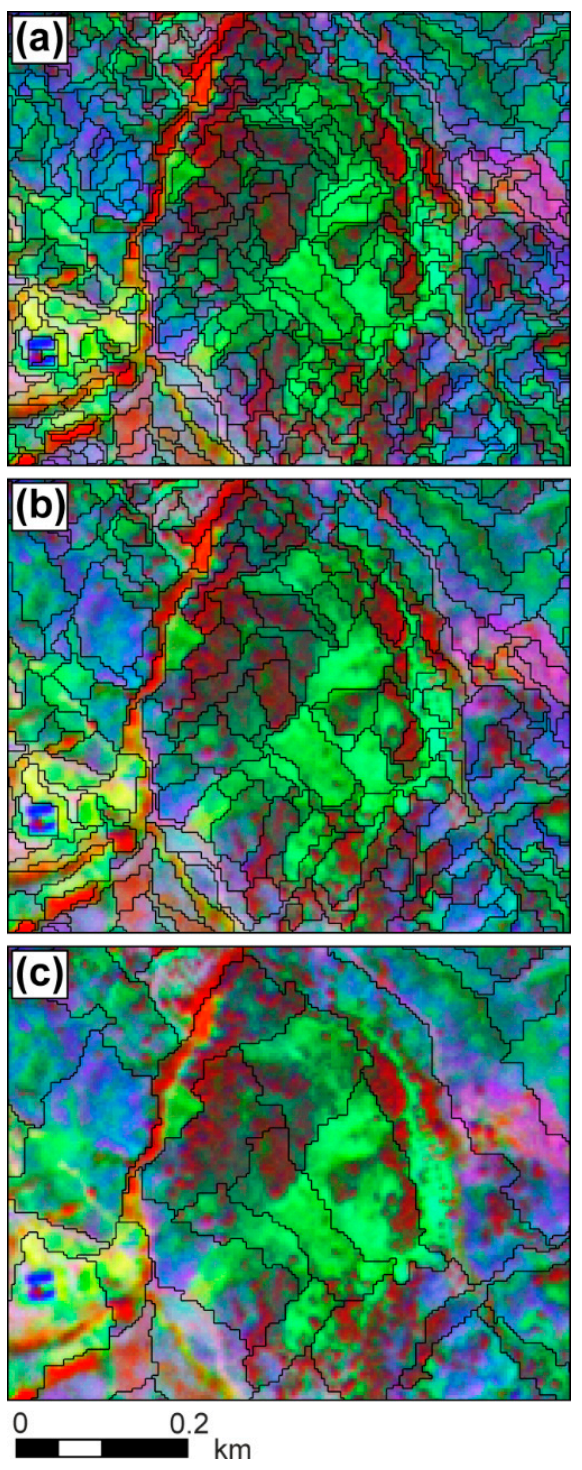

Figure 3. A subset of the segmentation results for scale parameter values of: (a) 1; (b) 2; and (c) 10. Black lines represent the borders of image objects. Background image is an RGB false-colour composite created using ATM MNF bands 1, 2, and 3, respectively (see Table 2). 
Table 3. Parameter values used to perform image segmentation for each input dataset (please refer to Table 2 for a description of the datasets).

\begin{tabular}{cccccc}
\hline Dataset & Scale & Colour & Shape & Smoothness & Compactness \\
\hline Li & 1 & 0.9 & 0.1 & 0.99 & 0.01 \\
ATM 9 & 1 & 0.9 & 0.1 & 0.99 & 0.01 \\
ATM PC & 1 & 0.9 & 0.1 & 0.99 & 0.01 \\
ATM MNF & 1 & 0.9 & 0.1 & 0.999 & 0.001 \\
ATM-Li & 1 & 0.99 & 0.01 & 0.999 & 0.001 \\
ATM-Li MNF & 1 & 0.99 & 0.01 & 0.99 & 0.01 \\
\hline
\end{tabular}

\subsubsection{Classification}

Following segmentation, image objects were assigned to one of the four lithologies using the supervised Standard Nearest Neighbour classification algorithm. This algorithm is non-parametric and assigns image objects to the class of their closest matching training sample in object feature space, with respect to a distance metric [51]. The object feature space can be defined in terms of the attributes such as the mean input band values of objects, the band standard deviations of objects and difference in mean band values between neighbouring objects [50]. In this study, the object means and standard deviations of the variables in each input datasets (detailed in Table 2) were selected as the object features on which to perform classification. A number of training sample objects representing each of the four lithological units were carefully identified in the segmented images, based on utilising extensive first-hand field knowledge of the study area in conjunction with very-high resolution $(0.7 \mathrm{~m})$ QuickBird satellite imagery. The existing lithological maps, shown in Figure 1c, were used to provide only a general geological overview given their coarseness and inconsistencies. The selected training sample objects were first used in conjunction with the eCognition Feature Space Optimisation tool to ensure that the object features associated with each of the six input datasets provided maximum discrimination between the four lithological units. The object features for each dataset were then subsequently used in conjunction with the training sample objects to perform lithological classification.

\subsection{Lithological Mapping Accuracy Assessment}

The usefulness of a lithological map is not only dependant on it displaying the correct lithologies outcropping at given locations, but also on how well it represents contacts (i.e., boundaries) between different units. Therefore, the accuracy of maps generated through the OBIA approach was assessed comprehensively in terms of both the thematic accuracy and the spatial accuracy of mapped lithological contacts.

\subsubsection{Thematic Accuracy}

A pixel-based thematic accuracy assessment was employed to readily enable a comparison between the OBIA and the equivalent SOM per-pixel classification approaches. To facilitate this, it is first necessary to convert the OBIA-based classification outputs to raster format. The accuracy of these maps was then assessed by computing the overall (OA), producer's (PA) and user's (UA) accuracies and the Kappa coefficient $(\mathrm{K})$ from a confusion matrix using a sample of validation pixels [52]. Upper and lower limits for the OA were also calculated for the $95 \%$ confidence interval based on the normal approximation [53]. The validation sample consisted of 12,946 pixels of known lithological identity ( $\geq 2451$ pixels representing each lithology), which were randomly selected from regions of interest (ROIs) in accordance with statistical sampling theory defining the minimum total and individual class sample sizes [54,55]. The ROIs representing each of the four units were again defined based on extensive field knowledge, QuickBird satellite imagery and, to a lesser extent, the existing lithological maps. 
The thematic accuracies of the OBIA approach were compared to those achieved for equivalent per-pixel classifications by testing for statistically significant differences. Since the same set of validation samples was used to determine the accuracies in both cases, the statistical significance of their differences was computed using the McNemar test [56]. This pair-wise test is based on the Chi-squared $\left(\chi^{2}\right)$ distribution, and involves cross-tabulation of the number of validation pixels correctly and incorrectly classified using the two different approaches:

$$
\chi^{2}=\frac{\left(f_{12}-f_{21}\right)^{2}}{f_{12}+f_{21}}
$$

where $f_{12}$ is the number of validation pixels correctly classified by the OBIA approach but incorrectly by the per-pixel approach, and $f_{21}$ is the number of validation pixels correctly classified by the per-pixel approach but incorrectly by the OBIA approach. The statistical significance of the difference is then determined based on tabulated $\chi^{2}$ values and expressed as a $p$-value $(p)$.

\subsubsection{Lithological Contact Accuracy}

The spatial accuracy of contacts delineated in maps produced by two approaches was assessed in terms of their correspondence to the validation mapping of reference contacts. This was achieved by implementing a methodology based on that of Salati et al. [9], which is outlined in Figure 4.

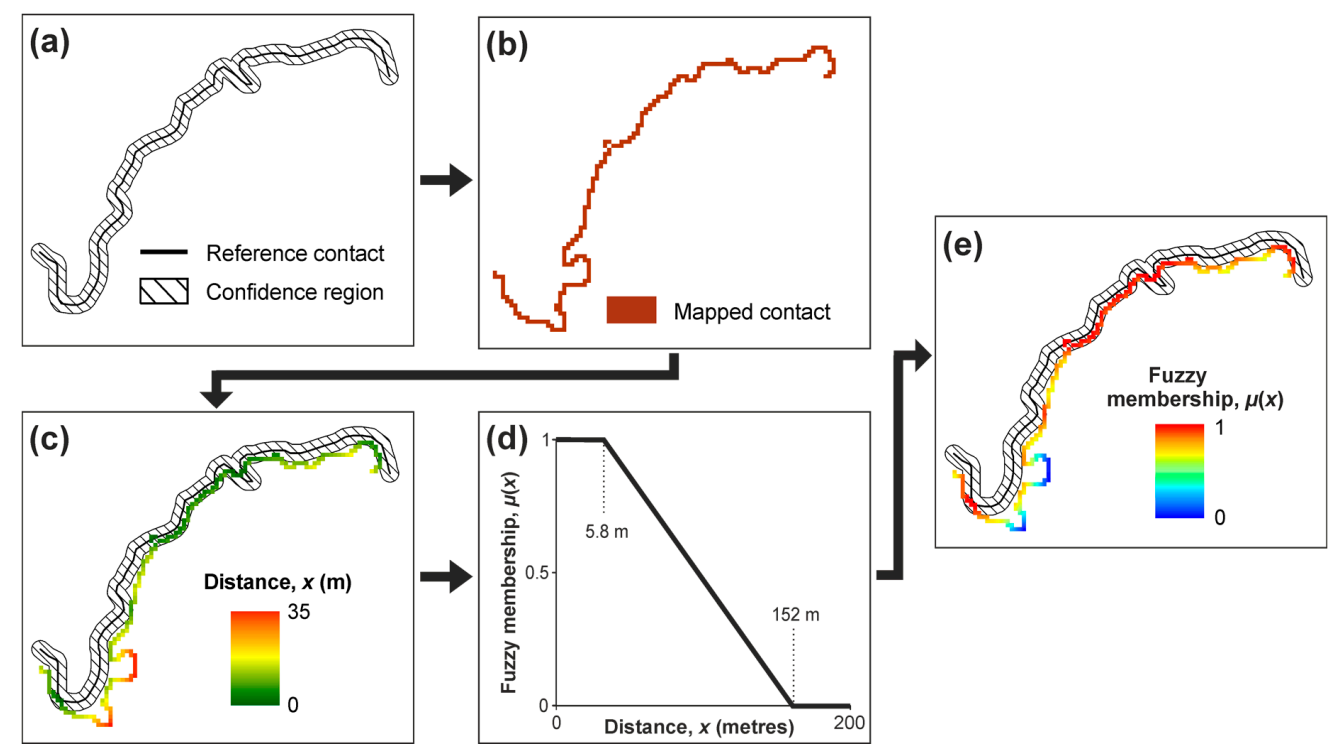

Figure 4. Assessing the accuracy of delineated contacts: (a) positional confidence region defined around reference contact; (b) equivalent contact in generated lithological map is identified; (c) distances between reference contact and pixels forming delineated contact are computed; (d) fuzzy membership function defined; and (e) fuzzy membership of contact pixels are computed.

This methodology employs fuzzy set theory to determine the spatial association between the delineated and reference contacts. In fuzzy set theory, elements are assigned a degree of membership to a set, with values ranging from 0 (i.e., not a member of the set) to 1 (i.e., a full member) on a continuous scale [57]. Here, membership represents the level of agreement between pixels constituting a contact in a derived lithological map and the reference contact. The contacts used as reference were mapped on a very-high resolution $(70 \mathrm{~cm})$ QuickBird image and further verified on the ground using a hand-held GPS. In total, more than $3 \mathrm{~km}$ of contacts were mapped for all feasible combinations of lithologies. To account for positional errors associated with the mapping scale and co-registration between the two source datasets, a confidence region was defined on both sides of the reference contacts. In keeping 
with Salati et al. [9], this buffer distance $(W)$ was calculated as the sum of the inherent map error $\left(E_{\mathrm{map}}\right)$ and co-registration error $\left(E_{\text {reg }}\right)$ :

$$
W=E_{\text {map }}+E_{\text {reg }}
$$

where $E_{\text {map }}$ is determined using the United States Geological Survey's map accuracy standard of $0.05 \mathrm{~cm}$ times the map scale [58], and $E_{\text {reg }}$ is the root-mean-square (RMS) co-registration error between the QuickBird imagery and the airborne data. For reference mapping at 1:5000-scale and a RMS co-registration error of $3.3 \mathrm{~m}$, the confidence region extends to a distance $(W)$ of $5.8 \mathrm{~m}$ from each reference contact.

Once confidence regions around the reference contacts have been established (Figure 4a), corresponding contacts in the generated maps were extracted and the distance between each constituent pixel and the reference contact were calculated (Figure $4 b, c)$. These distances were then converted to fuzzy membership values on the basis that contact pixels located closer to the reference contact have a high degree of membership:

$$
\mu(x)=\left\{\begin{array}{cl}
1, & x<\min (x) \\
0, & x>\max (x) \\
1-\left(\frac{x-\min (x)}{\max (x)-\min (x)}\right), & \min (x) \leq x \leq \max (x)
\end{array}\right.
$$

where $\mu(x)$ is the membership value, $x$ is the distance between a contact pixel and reference contact, and $\min (x)$ and $\max (x)$ are the minimum and maximum distances, respectively. The value of $\max (x)$ was set to $152 \mathrm{~m}$ to encompass all analysed contact pixels, whereas $\min (x)$ was set to equal to the confidence region $(5.8 \mathrm{~m})$ since all contact pixels within this region are assumed to coincide with the reference contact (i.e., they have a membership value of 1 ).

\section{Results and Discussion}

\subsection{Lithological Discrimination Using the OBIA Approach}

The capability of the OBIA approach in discriminating between the lithologies is described in Figures 5-7, as well as in the confusion matrices (Tables S1-S6 in the Supplementary Materials). For all six input datasets, the OA is in excess of $63 \%$, with an average and maximum OA of $69.4 \%$ and $73.5 \%$, respectively. Associated $\mathrm{K}$ values lie in the range $0.51-0.65$, indicating a moderate to substantial level of agreement between the classified maps and the validation data [59].

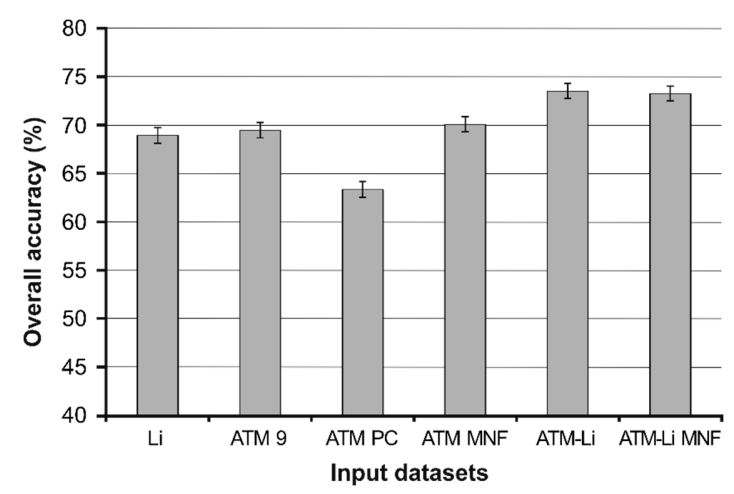

Figure 5. Overall accuracies (OA) of lithological maps generated by applying the OBIA approach to the six input datasets (see Table 2 for description). Error bars represent $95 \%$ confidence intervals.

Classification based solely on exploiting the topographic characteristics of the lithologies ( $\mathrm{Li}$; see Table 2) resulted in an OA of $68.9 \%$ ( $K=0.59$; Figure 5). This is comparable (i.e., not statistically different at the $95 \%$ confidence level; $p>0.05$ ) to the results attainable through indirect spectral discrimination by making use of the correlation between lithology and vegetation (ATM MNF: OA $=70.1 \%$; ATM 9: 
$\mathrm{OA}=69.5 \%)$. Furthermore, integration of the two strategies to simultaneously exploit the topographic and geobotanical characteristics is synergistic $(p<0.05)$, increasing the OA to more than $73 \%$ in both cases (ATM-Li and ATM-Li MNF). From Figure 6, it is apparent that this synergism is primarily due to enhanced mapping of the Basal Group and Alluvium-colluvium units following the incorporation of topographic information alongside the spectral imagery. The OBIA-derived maps for each set of input variables are shown in Figure 7. Visually, all six maps bear a remarkable resemblance to the existing geological maps (see Figure 1c), by portraying the abundant outcropping of Pillow Lavas in the southeastern portion of the study area, considerable alluvium-colluvium in the northwest, and Lefkara Formation cover in the northeast. Moreover, the maps depict the generalised surficial geology with a significantly higher level of detail, and provide additional information on outcropping of Alluvium-colluvium in the study area.

(a)

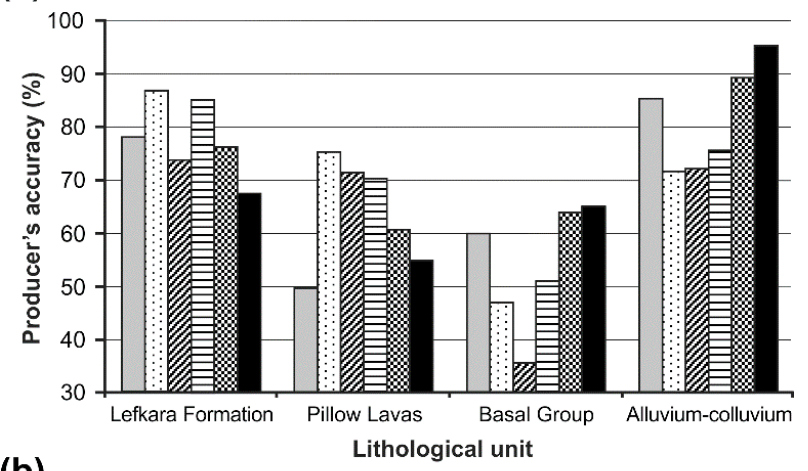

(b)

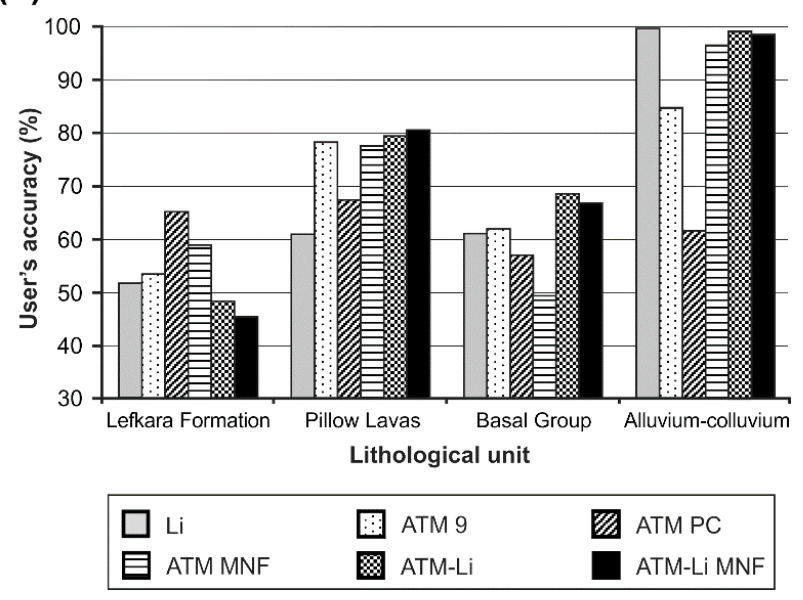

Figure 6. Individual lithological class accuracies of maps generated using the OBIA approach: (a) Producer's accuracy (PA); and (b) User's accuracy (UA).

Irrespective of the input dataset, Alluvium-colluvium is generally the most accurately mapped lithology, with consistently high PA and UA (Figure 6). This is because the Alluvium-colluvium unit is particularly distinctive in terms of both its topography and the types of vegetation it is typically associated with [26,34]. Although the Lefkara Formation is mapped with a high PA (>67\%), it is associated with relatively large commission errors $(34 \%-54 \%)$ as apparent through the notable abundance of incorrectly mapped Lefkara Formation in the southeastern portion of the study area (Figure 7e). The confusion matrices (Tables S1-S6 in the Supplementary Materials) reveal that this large commission error is primarily due to confusion with the Basal Group, which can be attributed to similarities in the types of vegetation found growing on both units [23]. The Basal Group itself is commonly confused with the Pillow Lavas, which is anticipated given that the distinction between these two units is one largely based on differences in the observed dyke abundance [60]. Nevertheless, 
the commission errors for the Pillow Lavas are low, particularly for classifications based on the spectral and integrated spectral-topographic input datasets (19\%-32\%). The confusion between Basal Group and Pillow Lavas is exacerbated in close proximity of Mathiati mine for classifications incorporating topographic information (Figure 7a,e,f), with the pit walls and flanks of the spoil heaps being incorrectly classified as Basal Group because of their artificial steep slopes. In contrast, the presence of Agia Varvara village in the north of the study area does not appear to pose any considerable hindrance to lithological mapping.
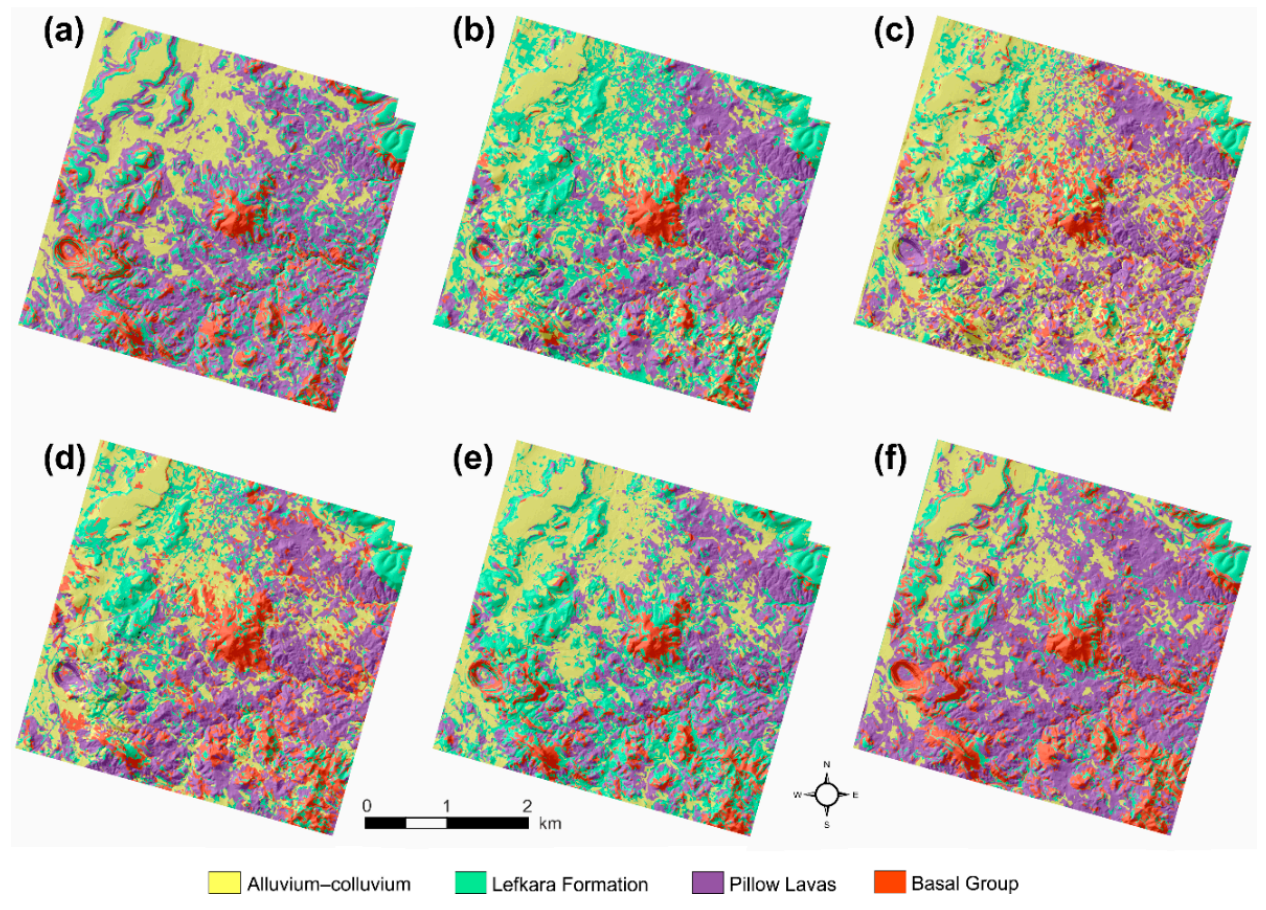

Figure 7. The OBIA-derived lithological maps for each input dataset: (a) Li; (b) ATM 9; (c) ATM PC; (d) ATM MNF; (e) ATM-Li; and (f) ATM-Li MNF.

\subsection{Comparison of OBIA and Per-Pixel Approaches to Lithological Discrimination}

Comparisons between thematic accuracies of equivalent OBIA and per-pixel classifications for all six input datasets are presented in Table 4. As mentioned above, the per-pixel results correspond to those obtained through classifications using the SOM artificial neural network as described by Grebby et al. [23]. In all cases, the OBIA approach outperforms its per-pixel equivalent ( $p<0.0001$ ), with an average difference of $5.7 \%$ and $16.6 \%$ in $\mathrm{OA}$ and $\mathrm{K}$, respectively. This is consistent with other studies, which similarly report increases of $7 \%-9 \%$ in OA and $\mathrm{K}$ in $9 \%-15 \%$ for OBIA classification of land cover/land use relative to per-pixel classification [27,36]; albeit significantly less than the differences (48.2\% in OA and 58.2\% in K) report by Munyati et al. [41] for delineation of geologically-controlled vegetation types. The greatest difference in mapping performance was observed for the ATM PC dataset, with the OBIA approach providing considerable increases of $13.1 \%$ in $\mathrm{OA}$ and $45.7 \%$ in $\mathrm{K}$ over its per-pixel counterpart. As the application of principal component analysis is found to accentuate the intra-class spectral variability [23], this result suggest that the OBIA approach is more effective than the per-pixel algorithm at discriminating lithologies in this landscape of heterogeneous surface cover. This is most likely because averaging together the values of all contiguous pixels within objects will act to reduce the intra-class variability that is observed when pixels are considered on an individual basis. The smallest difference between the two classifiers was observed for the ATM-Li MNF input dataset. Although the most accurate per-pixel approach (achieving an OA of 72.7\%), it is nonetheless still outperformed its OBIA counterpart by a small, 
but statistically significant difference $(p<0.0001)$, of $0.6 \%$ in OA. The best performing OBIA approach (ATM-Li) exceeded the OA of its per-pixel equivalent by $3.3 \%$. Irrespective of the classification approach, results do appear to reiterate the synergism of integrating multisource data to improve the distinction between lithologies.

Table 4. Comparison of overall accuracies (OA), Kappa coefficients (K) and statistical significance of differences ( $p$-value) between the OBIA and per-pixel approaches.

\begin{tabular}{cccccccc}
\hline \multirow{2}{*}{ Dataset } & \multicolumn{2}{c}{ OBIA } & & \multicolumn{2}{c}{ Per-Pixel } & \multirow{2}{*}{$\boldsymbol{p}$-Value } \\
\cline { 2 - 3 } & OA (\%) & $\mathbf{K}$ & & OA (\%) & $\mathbf{K}$ & \\
\hline Li & 68.9 & 0.59 & & 65.4 & 0.53 & $<0.0001$ \\
ATM 9 & 69.5 & 0.59 & & 60.3 & 0.48 & $<0.0001$ \\
ATM PC & 63.3 & 0.50 & & 50.2 & 0.35 & $<0.0001$ \\
ATM MNF & 70.1 & 0.60 & & 65.5 & 0.54 & $<0.0001$ \\
ATM-Li & 73.5 & 0.65 & & 70.2 & 0.60 & $<0.0001$ \\
ATM-Li MNF & 73.3 & 0.63 & & 72.7 & 0.63 & $<0.0001$ \\
\hline
\end{tabular}

Although each OBIA approach outperforms its per-pixel counterpart in terms of OA, the performance in terms of mapping individual lithologies is somewhat variable between classifiers and input datasets (Figure 8). For example, despite the ATM-Li OBIA approach resulting in the highest $\mathrm{OA}$, it produces lower PA and UA for some lithologies (e.g., Lekara Formation) than its per-pixel equivalent (Figure 8e), as well as other OBIA classifications (e.g., ATM 9; Figure 8b). Such variability could be an indication that a single scale value is not optimal for segmenting all lithological classes [58]. Nevertheless, when considering each type of classifier on the whole, the overall superiority of the OBIA approach over that of the per-pixel approach is generally attributable to enhanced discrimination of the Lefkara Formation and Alluvium-colluvium units (Figure 8). For the Lefkara Formation, this is evident through increases in the average PA and UA of $7.9 \%$ and $6.1 \%$, respectively, when the results for all six input datasets are considered. Visually, this is particularly apparent through the improved mapping of outcrops in the northeast of the study area, even when the best overall OBIA (ATM-Li) and per-pixel (ATM-Li MNF) approaches are compared (Figure 9, bottom zoom extent). Given the significant degree of intra-class variability and overlap in the spectral and topographic characteristics of the Lefkara Formation with those of other units [23,46], the observed increases in PA and UA over the per-pixel approach are again most likely due to the averaging effect leading to a reduction in the intra-class variability and enhanced separation between classes; again reaffirming the main rational for utilising OBIA over per-pixel approaches [34,35].

The improved mapping of Alluvium-colluvium through the OBIA approach is largely associated with consistent decreases in the commission error for the Pillow Lavas. This is most apparent in the north and northwestern portion of the study area, where an abundance of Pillow Lavas mapped using the per-pixel approach is correctly reassigned to Alluvium-colluvium through use of the OBIA approach (Figure 9, top zoom extent). However, relative to the per-pixel approach, most observed increases in the Basal Group PA for the OBIA approach are offset by similar decreases in the UA when topographic variables are incorporated (Figure 8a,e,f). Furthermore, in all cases, relative increases in the UA for the Pillow Lavas are offset by comparable decreases in the PA. These are somewhat surprising observations given that the Basal Group has distinctive topographic characteristics, whilst the Pillow Lavas are also distinctive in terms of both their associated vegetation and topography. This lack of consistent improvement suggests that that there is little or no overall benefit in employing the OBIA approach over the per-pixel approach to discriminate units with relatively low intra-class variability. Alternatively, it could again suggest that a single scale value is not optimal for segmenting all lithological classes. Irrespective of this, it is clear that the OBIA approach employed here is effective in reducing the "salt-and-pepper" artefact associated with per-pixel classification (Figure 9). Consequently, the OBIA approach is capable of enabling more veracious and contiguous mapping of lithological units. This concurs with the findings of Kassouk et al. [39], who demonstrate the ability to 
use OBIA for delineating homogeneous geological units on Merapi volcano (Indonesia) despite the hindrance posed by variable overlying tephra cover and pyroclastic density currents.
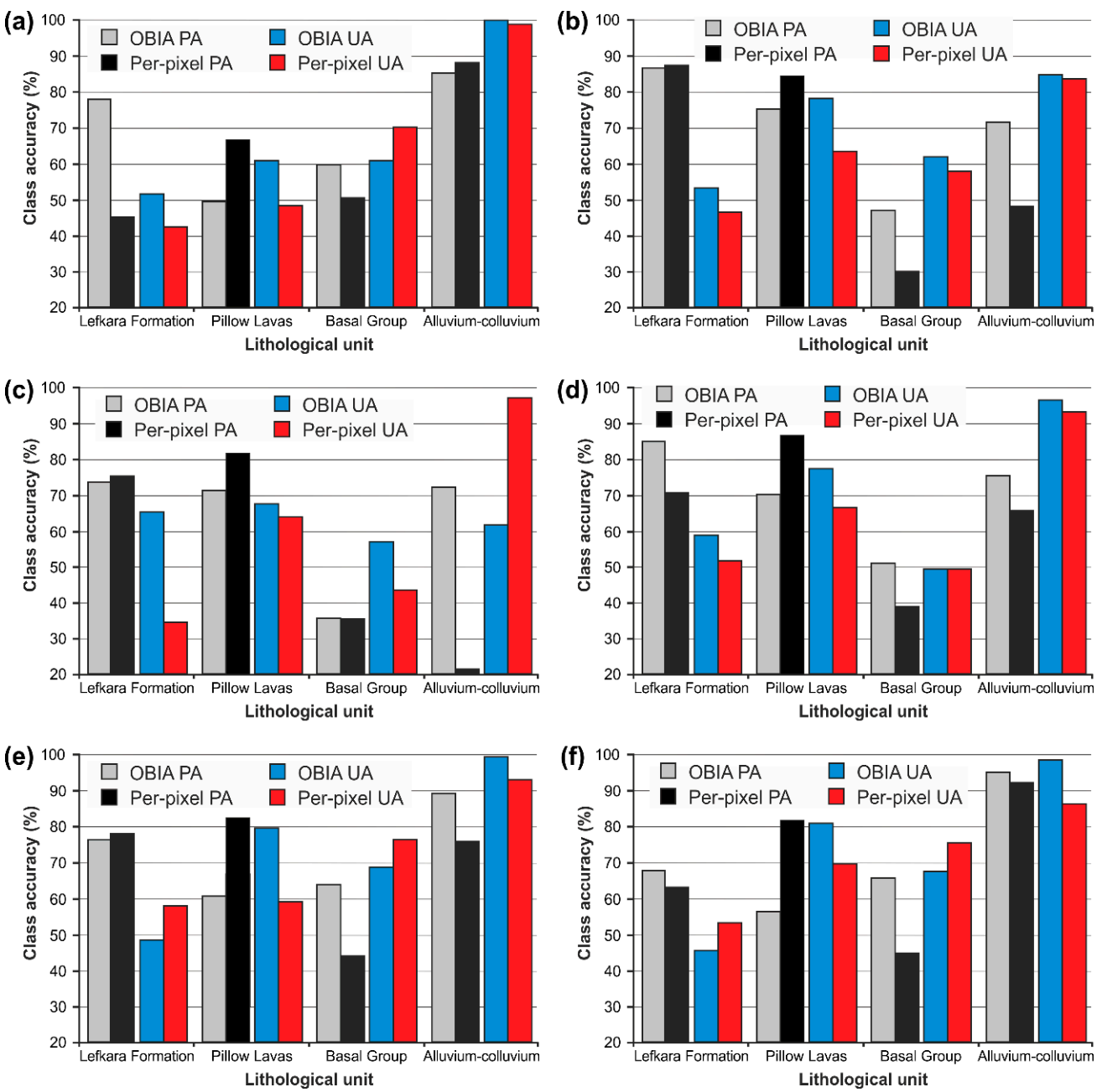

Figure 8. Comparison of the Producer's (PA) and User's (UA) accuracies for equivalent OBIA and per-pixel classifications: (a) Li; (b) ATM 9; (c) ATM PC; (d) ATM MNF; (e) ATM-Li; and (f) ATM-Li MNF.

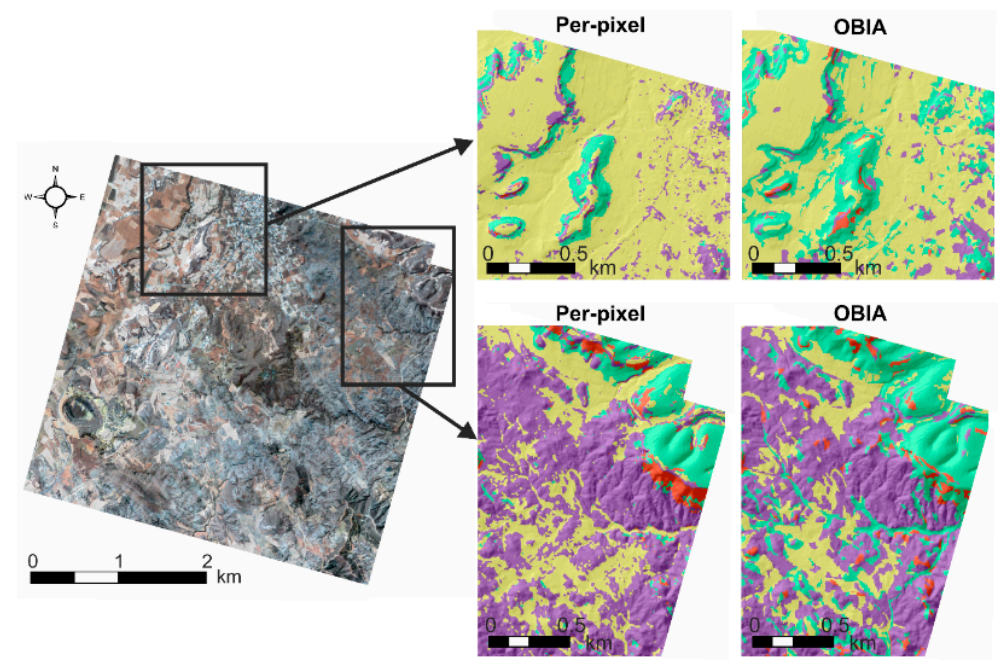

Figure 9. Comparison of the mapping results generated using the best OBIA (ATM-Li) and per-pixel (ATM-Li MNF) approaches. 


\subsection{Lithological Contact Mapping Performance}

The fuzzy membership scores, which measure the spatial accuracy of lithological contacts delineated in the lithological maps with respect to reference contacts, are shown in Figure 10, for both the OBIA and per-pixel approaches. Of the six OBIA classifications, that based on the ATM 9 input dataset (Figure 10b) was the most accurate at defining contacts, with $41.4 \%$ of delineated contact pixels found to fall with the defined confidence regions (i.e., having a fuzzy membership score of 1). This is followed closely by classifications based on the ATM PC (Figure 10c) and ATM MNF (Figure 10d) input datasets, both for which $36.8 \%$ of contact pixels fall within the confidence regions. The worst results were achieved for the ATM-Li dataset (Figure 10e), with only 15.9\% of delineated contact pixels found to fall with the defined confidence regions. In fact, all three OBIA classifications that incorporate the topographic input variables ( $\mathrm{Li}, 22.3 \%$; and ATM-Li MNF, 25.2\%) performed worse at mapping lithological contacts than those based solely on the spectral variables. This is likely because sharp topographic transitions marking the contact between lithologies are smoothed somewhat through use of moving windows in the derivation of the geomorphometric input variables [46].

Despite the variability between input datasets, the OBIA approach generally outperforms its per-pixel counterpart in mapping lithological contacts, by delineating (in five out of the six cases) between $3.2 \%$ and $15.3 \%$ more contact pixels that lie within the confidence regions. The greatest different was observed for the ATM PC input dataset (Figure 10c), with $36.8 \%$ and $21.5 \%$ of contact pixels falling within the confidence regions for the OBIA and per-pixel approaches, respectively. A similar difference in performance between the two approaches is observed when pixels proximal to the confidence regions are considered, with 58.8\% of OBIA-mapped contact pixels having a fuzzy membership score of $0.95-1.0$, compared to $43.1 \%$ for the per-pixel approach. The smallest difference (25.2\% vs. $22.0 \%$ ) was observed for the ATM-Li MNF input dataset (Figure 10f), although extending the catchment area reveals that the per-pixel approach delineates a slightly higher proportion of contact pixels with fuzzy membership score of $0.95-1.0$ than its OBIA equivalent (47.0\% vs. $40.5 \%$ ). Nonetheless, on the whole, the results clearly demonstrate that grouping contiguous pixels into objects is more effective for mapping lithological contacts than classifying on a per-pixel basis. Notably, the OBIA approach was found to be most advantageous in delineating Pillow Lava-Alluvium-colluvium contacts, as well as more irregular Pillow Lava-Lefkara Formation contacts.

(a)

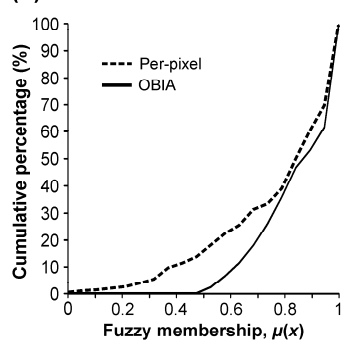

(d)

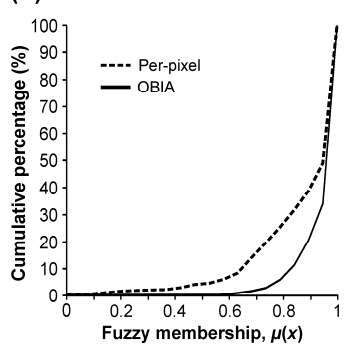

(b)

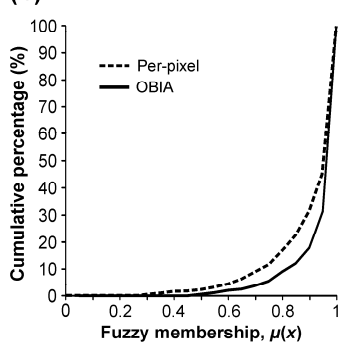

(e)

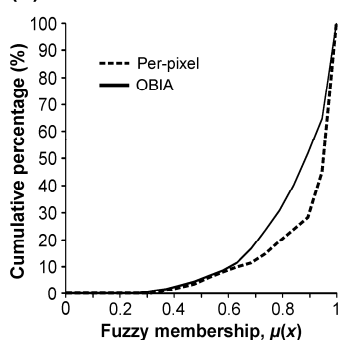

(c)

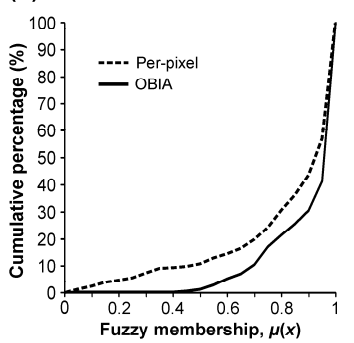

(f)

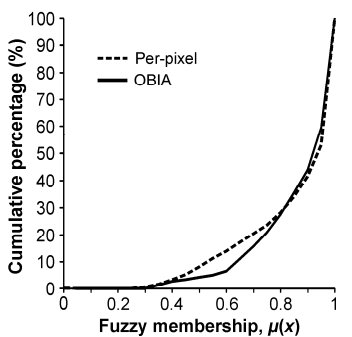

Figure 10. Comparison of fuzzy membership scores assigned contact pixels delineated using equivalent OBIA and per-pixel classifications: (a) Li; (b) ATM 9; (c) ATM PC; (d) ATM MNF; (e) ATM-Li; and (f) ATM-Li MNF. 
Of the six cases, the ATM-Li input dataset is the only case for which the per-pixel approach was actually found to outperform the OBIA approach in terms of contact mapping (Figure 10e). Specifically, $23.8 \%$ of per-pixel mapped contact pixels were found to coincide with the confidence regions, compared with only $15.9 \%$ for the OBIA approach. For the wider area, this difference increases with $54.8 \%$ and $35.1 \%$ of per-pixel and OBIA contact pixels, respectively, assigned fuzzy membership scores of 0.95-1.0. However, since the OBIA approach outperforms the per-pixel approach in mapping contacts in the five other cases-including the other integrated spectral-topographic input dataset (ATM-Li MNF) - this conflicting result could be due to a sub-optimal segmentation outcome. In any case, this reiterates how critical the segmentation stage is and the influence it can have on the classified output $[28,61,62]$. As mentioned above, the segmentation process is still largely dependent on the "trial-and-error" approach, owing to the absence of a universally accepted method for determining the optimal segmentation parameters. In addition, this heuristic approach to optimising segmentation can be time consuming and, as a consequence, some per-pixel approaches may be more efficient than OBIA. However, in the case of advanced per-pixel classification algorithms (such as the SOM neural network used here), an equally time consuming "trial-and-error" approach is also commonly required to optimise the network parameters. Nevertheless, it is worth noting that there are on-going attempts to devise more quantitative and automated segmentation parameter selection methods [63-65], which are anticipated to help increase the efficiency and optimisation of this process, and ultimately produce better results than currently attainable through "trial-and-error" [50].

\section{Conclusions}

This first-of-its-kind study evaluates the capability of an OBIA approach for indirectly mapping lithologies in a vegetated landscape using airborne multispectral imagery and airborne LiDAR data. The devised method consists of three steps: input feature selection, segmentation and classification. This approach was used in conjunction with different types of input variables (i.e., spectral, topographic, and integrated spectral-topographic), which were designed to exploit geobotanical associations and the correlation between lithology and topography. In all six cases, the OBIA approach was found to significantly outperform its equivalent per-pixel approach (utilising an SOM artificial neural network classifier) in terms of thematic accuracy. This enhanced ability to differentiate between lithologies is attributed to the averaging effect within objects, which reduces the intra-class variability predominantly caused both heterogeneous vegetation cover and natural deviations from the topographical characteristics of individual lithologies. Moreover, in five of the six of the assessed cases, the OBIA approach successfully delineated lithological contacts with a greater spatial accuracy than the per-pixel approach. However, the converse was true for the ATM-Li input dataset, which was attributed to sub-optimal segmentation. This further highlights the need for an objective, universally-accepted approach for determining the optimal segmentation parameters, and thus maximising the potential of the OBIA approach. Nevertheless, the overall results of this study clearly demonstrate that the OBIA approach offers the potential to produce more realistic and accurate lithological maps than per-pixel approaches in significantly vegetated and heterogeneous terrain. Despite this, it is also clear from the result that there is not a single optimal OBIA classification approach to lithological mapping. For instance, the best input dataset with respect to thematic mapping is actually the worst at accurately delineating contacts (ATM-Li). Similarly, the dataset providing the highest OA in terms of thematic accuracy does not necessarily map all individual lithologies with the highest accuracies. This implies that a trade-off may be required when selecting a model that achieves both satisfactory thematic and contact mapping results.

Although this study currently presents the most comprehensive assessment of an OBIA approach to lithological mapping, further studies utilising different types of data (e.g., very-high resolution satellite, and hyperspectral) and in different geological settings are required to help fully realise the efficacy of object-based approach. For instance, in this case, the topographic and geobotanical characteristics are relatively homogeneous within lithological units whilst sufficiently distinct between 
them to permit indirect mapping. However, the efficacy of this type of indirect approach may be limited over larger areas or in more heterogeneous landscapes, where spatial variation in both vegetation and earth surface processes (e.g., weathering, erosion, and faulting) could be greater, therefore hindering adequate characterisation of lithologies using proxy information. However, as indicated here, an OBIA approach is still likely to be more effective than pixel-based approaches in reducing the impact of this intra-class variability.

In its current form, the OBIA approach presented here is somewhat time consuming due to manual optimisation of the segmentation parameters. Nonetheless, by producing detailed reconnaissance maps with accurately defined contacts, an approach such as this can still ultimately help to reduce the time and cost of geological mapping programmes, by enabling more efficient, targeted field mapping.

Supplementary Materials: The following are available online at www.mdpi.com/2072-4292/8/10/843/s1, Table S1: Confusion matrix for the OBIA classification of the Li dataset, Table S2: Confusion matrix for the OBIA classification of the ATM 9 dataset, Table S3: Confusion matrix for the OBIA classification of the ATM PC dataset, Table S4: Confusion matrix for the OBIA classification of the ATM MNF dataset, Table S5: Confusion matrix for the OBIA classification of the ATM-Li dataset, Table S6: Confusion matrix for the OBIA classification of the ATM-Li MNF dataset.

Acknowledgments: This work was primarily supported via a BGS University Funding Initiative bursary awarded to Elena Field. We gratefully acknowledge the NERC ARF (grant) MC04/30 for data acquisition, and Stelios Nicolaides (Geological Survey Department of Cyprus) and Simon Jowitt (University of Nevada Las Vegas) for invaluable logistical and scientific help in the field. We also express our gratitude to Luke Bateson (BGS) and Danny Donoghue (Durham University) for AZGCORR and Terrasolid software support, respectively. Colm Jordan (BGS) is also thanked for providing comments on an early draft of this manuscript. We are grateful to the four anonymous reviewers, whose comments and suggestions have help to greatly improve the quality of the manuscript.

Author Contributions: Stephen Grebby conceived the study, performed the initial processing of the remotely sensed data and undertook the fieldwork for validation purposes. The analysis was jointly undertaken by Stephen Grebby and Elena Field. The manuscript was written by Stephen Grebby with input from all authors.

Conflicts of Interest: The authors declare no conflict of interest.

\section{References}

1. Cracknell, M.J.; Reading, A.M. Geological mapping using remote sensing data: A comparison of five machine learning algorithms, their response to variations in the spatial distribution of training data and the use of explicit spatial information. Comput. Geosci. 2014, 63, 22-33. [CrossRef]

2. Asadzadeh, S.; de Souza Filho, C.R. A review on spectral processing methods for geological remote sensing. Int. J. Appl. Earth Obs. Geoinf. 2016, 47, 69-90. [CrossRef]

3. Van der Meer, F. The effectiveness of spectral similarity measures for the analysis of hyperspectral imagery. Int. J. Appl. Earth Obs. Geoinf. 2006, 8, 3-17. [CrossRef]

4. Van der Meer, F.D.; van der Werff, H.M.A.; van Ruitenbeek, F.J.A.; Hecker, C.A.; Bakker, W.H.; Noomen, M.F.; van der Meijde, M.; Carranza, E.J.M.; de Smeth, J.B.; Woldai, T. Multi- and hyperspectral geologic remote sensing: A review. Int. J. Appl. Earth Obs. Geoinf. 2012, 14, 112-128. [CrossRef]

5. Rothery, D.A. Reflectances of ophiolite rocks in the Landsat MSS bands: Relevance to lithological mapping by remote sensing. J. Geol. Soci. 1984, 141, 933-939. [CrossRef]

6. Ricchetti, E. Multispectral satellite image and ancillary data integration for geological classification. Photogramm. Eng. Remote Sens. 2000, 66, 429-435.

7. An, P.; Chung, C.F.; Rencz, A.N. Digital lithology mapping from airborne geophysical and remote sensing data in the Melville Peninsula, northern Canada, using a neural network approach. Remote Sens. Environ. 1995, 53, 76-84. [CrossRef]

8. Bedini, E. Mapping lithology of the Sarfartoq carbonatite complex, southern West Greenland, using HyMap imaging spectrometer data. Remote Sens. Environ. 2009, 113, 1208-1219. [CrossRef]

9. Salati, S.; van Ruitenbeek, F.J.A.; van der Meer, F.D.; Tangestani, M.H.; van der Werff, H. Lithological mapping and fuzzy set theory: Automated extraction of lithological boundary from ASTER imagery by template matching and spatial accuracy assessment. Int. J. Appl. Earth Obs. Geoinf. 2011, 13, 753-765. [CrossRef] 
10. Mustard, J.F.; Pieters, C.M. Abundance and distribution of ultramafic microbreccia in Moses Rock Dike: Quantitative application of mapping spectroscopy. J. Geophys. Res. 1987, 92, 10376-10390. [CrossRef]

11. Bowers, T.L.; Rowan, L.C. Remote mineralogic and lithologic mapping of the Ice River Alkaline Complex, British Columbia, Canada, using AVIRIS data. Photogramm. Eng. Remote Sens. 1996, 62, 1379-1385.

12. Leverington, D.W.; Moon, W.M. Landsat-TM-based discrimination of lithological units associated with the Purtiniq ophiolite, Quebec, Canada. Remote Sens. 2012, 4, 1208-1231. [CrossRef]

13. Harris, J.R.; McGregor, R.; Budkewitsch, P. Geological analysis of hyperspectral data over southwest Baffin Island: Methods for producing spectral maps that relate to variations in surface lithologies. Can. J. Remote Sens. 2010, 36, 412-435. [CrossRef]

14. Siegal, B.S.; Goetz, A.F.H. Effect of vegetation on rock and soil type discrimination. Photogramm. Eng. Remote Sens. 1977, 43, 191-196.

15. Ager, C.M.; Milton, N.M. Spectral reflectance of lichens and their effects on the reflectance of rock substrates. Geophysics 1987, 52, 898-906. [CrossRef]

16. Bierwirth, P.N. Mineral mapping and vegetation removal via data-calibrated pixel unmixing, using multispectral images. Int. J. Remote Sens. 1990, 11, 1999-2017. [CrossRef]

17. Zhang, J.; Rivard, B.; Sanchez-Azofeifa, A. Spectral unmixing of normalized reflectance data for the deconvolution of lichen and rock mixtures. Remote Sens. Environ. 2005, 95, 57-66. [CrossRef]

18. Paradella, W.R.; Vitorello, I. Geobotanical and soil spectral investigation for rock discrimination in the 'Caatinga' environment (Brazil) based on multitemporal remote sensing data. Can. J. Remote Sens. 1995, 21, 52-59. [CrossRef]

19. Harris, J.R.; Rogge, D.; Hitchcock, R.; Ijewliw, O.; Wright, D. Mapping lithology in Canada's Arctic: Application of hyperspectral data using the minimum noise fraction transformation and matched filtering. Can. J. Earth Sci. 2005, 42, 2173-2193. [CrossRef]

20. Kühni, A.; Pfiffner, O.A. The relief of the Swiss Alps and adjacent areas and its relation to lithology and structure: Topographic analysis from a 250-m DEM. Geomorphology 2001, 41, 285-307. [CrossRef]

21. Belt, K.; Paxton, S.T. GIS as an aid to visualizing and mapping geology and rock properties in regions of subtle topography. Geol. Soc. Am. Bull. 2005, 117, 149-160. [CrossRef]

22. Mather, P.M.; Tso, B.; Koch, M. An evaluation of Landsat TM spectral data and SAR-derived textural information for lithological discrimination in the Red Sea Hills, Sudan. Int. J. Remote Sens. 1998, 19, 587-604. [CrossRef]

23. Grebby, S.; Naden, J.; Cunningham, D.; Tansey, K. Integrating airborne multispectral imagery and airborne LiDAR data for enhanced lithological mapping in vegetated terrain. Remote Sens. Environ. 2011, 115, 214-226. [CrossRef]

24. Blaschke, T.; Hay, G.J.; Kelly, M.; Lang, S.; Hofmann, P.; Addink, E.; Queiroz Feitosa, R.; van der Meer, F.; van der Werff, H.; van Coillie, F.; Tiede, D. Geographic object-based image analysis-Towards a new paradigm. ISPRS J. Photogramm. 2014, 87, 180-191. [CrossRef] [PubMed]

25. Baatz, M.; Schäpe, A. Multiresolution segmentation: An optimization approach for high quality multi-scale image segmentation. Angew. Geogr. Informationsverarbeitung XII 2000, 58, 12-23.

26. Blaschke, T. Object based image analysis for remote sensing. ISPRS J. Photogramm. 2010, 65, 2-16. [CrossRef]

27. Whiteside, T.G.; Boggs, G.S.; Maier, S.W. Comparing object-based and pixel-based classifications for mapping savannas. Int. J. Appl. Earth Obs. Geoinf. 2011, 13, 884-893. [CrossRef]

28. Dorren, L.K.A.; Maier, B.; Seijmonsbergen, A.C. Improved Landsat-based forest mapping in steep mountainous terrain using object-based classification. Forest Ecol. Manag. 2003, 183, 31-46. [CrossRef]

29. Dronova, I.; Gong, P.; Wang, L. Object-based analysis and change detection of major wetland cover types and their classification uncertainty during the low water period at Poyang Lake, China. Remote Sens. Environ. 2011, 115, 3220-3236. [CrossRef]

30. Antonarakis, A.S.; Richards, K.S.; Brasington, J. Object-based land cover classification using airborne LiDAR. Remote Sens. Environ. 2008, 112, 2988-2998. [CrossRef]

31. Lucieer, A.; Stein, A. Texture-based landform segmentation of LiDAR imagery. Int. J. Appl. Earth Obs. Geoinf. 2005, 6, 261-270. [CrossRef]

32. Drăguț, L.; Blaschke, T. Automated classification of landform elements using object-based image analysis. Geomorphology 2006, 81, 330-344. [CrossRef] 
33. Im, J.; Jensen, J.R.; Tullis, J.A. Object-based change detection using correlation image analysis and image segmentation. Int. J. Remote Sens. 2008, 29, 399-423. [CrossRef]

34. Yu, Q.; Gong, P.; Clinton, N.; Biging, G.; Kelly, M.; Schirokauer, D. Object-based detailed vegetation classification with airborne high spatial resolution sensing imagery. Photogramm. Eng. Remote Sens. 2006, 72, 799-811. [CrossRef]

35. Castillejo-González, I.L.; López-Granados, F.; García-Ferrer, A.; Peña-Barragán, J.M.; Jurado-Expósito, M.; Sánchez de la Ordena, M.; González-Audicana, M. Object- and pixel-based analysis for mapping crops and their agro-environmental associated measures using QuickBird imagery. Comput. Electron. Agric. 2009, 68, 207-215. [CrossRef]

36. Myint, S.W.; Gober, P.; Brazel, A.; Grossman-Clarke, S.; Weng, Q. Per-pixel vs. object-based classification of urban land cover extraction using high spatial resolution imagery. Remote Sens. Environ. 2011, 115, 1145-1161. [CrossRef]

37. Lucieer, A.; Orkhonselenge, T.; Stein, A. Texture-based segmentation for identification of geological units in remotely sensed imagery. In Proceedings of the 3rd International Symposium on Spatial Data Quality (ISSDQ), Bruck an der Leitha, Austria, 15-17 April 2004.

38. Van der Werff, H.; van Ruitenbeek, F.; van der Meer, F. Geological mapping on Mars by segmentation of hyperspectral OMEGA data. In Proceedings of the Geoscience and Remote Sensing Symposium (IGARSS), IEEE International, Barcelona, Spain, 23-28 July 2007.

39. Kassouk, Z.; Thouret, J.-C.; Gupta, A.; Solikhin, A.; Liew, S.C. Object-oriented classification of a high-spatial resolution SPOT5 image for mapping geology and landforms of active volcanoes: Semeru case study, Indonesia. Geomorphology 2014, 221, 18-33. [CrossRef]

40. Thouret, J.C.; Kassouk, Z.; Gupta, A.; Liew, S.C.; Solikhin, A. Tracing the evolution of 2010 Merapi volcanic deposits (Indonesia) based on object-oriented classification and analysis of multi-temporal very high resolution images. Remote Sens. Environ. 2015, 170, 350-371. [CrossRef]

41. Munyati, C.; Ratshibvumo, T.; Ogola, J. Landsat TM image segmentation for delineating geological zone correlated vegetation stratification in the Kruger National Park, South Africa. Phys. Chem. Earth 2013, 55, 1-10. [CrossRef]

42. Gass, I.G. Is the Troodos massif of Cyprus a fragment of mesozoic ocean crust? Nature 1968, 220, 39-42. [CrossRef]

43. Varga, R.J.; Moores, E.M. Spreading structure of the Troodos ophiolite, Cyprus. Geology 1985, 13, 846-850. [CrossRef]

44. Gass, I.G. The Geology and Mineral Resources of the Dhali Area; Cyprus Geological Survey Department: Lefkosia, Cyprus, 1960.

45. Constantinou, G. Geological Map of Cyprus, Scale 1:250,000; Cyprus Geological Survey Department: Lefkosia, Cyprus, 1995.

46. Grebby, S.; Cunningham, D.; Naden, J.; Tansey, K. Lithological mapping of the Troodos ophiolite, Cyprus, using airborne LiDAR topographic data. Remote Sens. Environ. 2010, 114, 713-724. [CrossRef]

47. Axelsson, P. DEM generation from laser scanner data using adaptive TIN models. Int. Arch. Photogramm. Remote Sens. 2000, 33, 110-117.

48. Grebby, S.; Cunningham, D.; Tansey, K.; Naden, J. The impact of vegetation on lithological mapping using airborne multispectral data: A case study for the North Troodos region, Cyprus. Remote Sens. 2014, 6, 10860-10887. [CrossRef]

49. Benz, U.C.; Hofmann, P.; Willhauck, G.; Lingenfelder, I.; Heynen, M. Multi-resolution, object-oriented fuzzy analysis of remote sensing data for GIS-ready information. ISPRS J. Photogramm. 2004, 58, 239-258. [CrossRef]

50. Duro, D.C.; Franklin, S.E.; Dubé, M.G. A comparison of pixel-based and object-based image analysis with selected machine learning algorithms for the classification of agricultural landscapes using SPOT-5 HRG imagery. Remote Sens. Environ. 2012, 118, 259-272. [CrossRef]

51. Trimble. eCognition Developer 9.1 User Guide; Trimble Documentation: Munich, Germany, 2015.

52. Congalton, R.G. A review of assessing the accuracy of classifications of remotely sensed data. Remote Sens. Environ. 1991, 37, 35-46. [CrossRef]

53. Foody, G.M. Sample size determination for image classification accuracy assessment and comparison. Int. J. Remote Sens. 2009, 30, 5273-5291. [CrossRef] 
54. Tortora, R.D. A note on sample size estimation for multinomial populations. Am. Stat. 1978, 32, $100-102$.

55. Fitzpatrick-Lins, K. Comparison of sampling procedures and data analysis for a land-use and land-cover map. Photogramm. Eng. Remote Sens. 1981, 47, 343-351.

56. Foody, G.M. Thematic map comparison: Evaluating the statistical significance of differences in classification accuracy. Photogramm. Eng. Remote Sens. 2004, 70, 627-633. [CrossRef]

57. Zadeh, L.A. Fuzzy sets. Inform. Control 1965, 8, 338-353. [CrossRef]

58. U.S. Geological Survey. Map Accuracy Standards. Available online: http://pubs.usgs.gov/fs/1999/0171/ (accessed on 15 April 2016).

59. Landis, J.R.; Koch, G.G. The measurement of observer agreement for categorical data. Biometrics 1977, 33, 159-174. [CrossRef] [PubMed]

60. Bear, L.M. The Geology and Mineral Resources of the Akaki-Lythrodondha Area; Geological Survey Department: Lefkosia, Cyprus, 1960.

61. Kim, M.; Madden, M.; Warner, T.A. Forest type mapping using object-specific texture measures from multispectral Ikonos imagery: Segmentation quality and image classification issues. Photogramm. Eng. Remote Sens. 2009, 75, 819-829. [CrossRef]

62. Kavzoglu, T.; Yildiz, M. Parameter-based performance analysis of object-based image analysis using aerial and Quickbird-2 images. ISPRS Ann. Photogramm. Remote Sens. Spat. Inform. Sci. 2014, II-7, 31-37. [CrossRef]

63. Espindola, G.M.; Camara, G.; Reis, I.A.; Bins, L.S.; Monteiro, A.M. Parameter selection for region-growing image segmentation algorithms using spatial autocorrelation. Int. J. Remote Sens. 2006, 27, 3035-3040.

64. Drăguț, L.; Tiede, D.; Levick, S.R. ESP: A tool to estimate scale parameter for multiresolution image segmentation of remotely sensed data. Int. J. Geogr. Inf. Sci. 2010, 24, 859-871. [CrossRef]

65. Anders, N.S.; Seijmonsbergen, A.C.; Bouten, W. Segmentation optimization and stratified object-based analysis for semi-automated geomorphological mapping. Remote Sens. Environ. 2011, 115, 2976-2985. [CrossRef]

(C) 2016 by the authors; licensee MDPI, Basel, Switzerland. This article is an open access article distributed under the terms and conditions of the Creative Commons Attribution (CC-BY) license (http://creativecommons.org/licenses/by/4.0/). 